\title{
CHINESE SOCIAL MEDIA STRATEGIES: COMMUNICATION KEY FEATURES FROM A BUSINESS PERSPECTIVE
}

\author{
Estrategias de marketing y comunicación en medios \\ sociales chinos: características clave de comunicación des- \\ de una perspectiva de negocio
}

Xia He and Rafael Pedraza-Jiménez
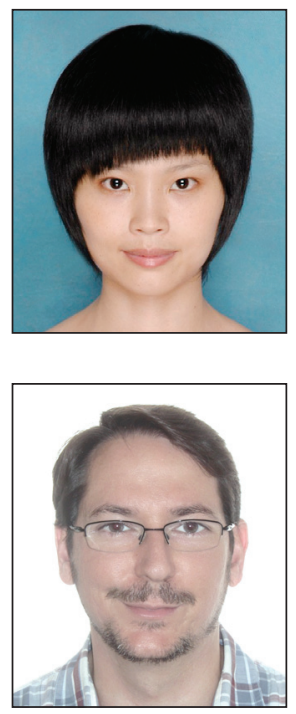

Xia He is a PhD student in the Department of Communication at the Universitat Pompeu Fabra and a researcher in the program of doctors training from China Scholarship Council. http://orcid.org/0000-0003-4092-0621

xia.he01@estudiant.upf.edu

Rafael Pedraza-Jiménez is a professor at Universitat Pompeu Fabra. He develops his teaching and research activities in the Digital and Interactive Formats Area and as a member of the DigiDoc Research Group.

http://orcid.org/0000-0002-6918-6910

rafael.pedraza@upf.edu

Departamento de Comunicación, Universitat Pompeu Fabra Roc Boronat, 138. 08018 Barcelona, España

\begin{abstract}
Some of the most attractive economies are located in emerging markets. In this sense, China is one of the most attractive markets in the world. The Web, especially social media, is a platform that can be used to penetrate these markets. Yet, many local and multinational enterprises, particularly the latter, know little about the relationship between Chinese social media and Chinese digital consumers. In this paper the unique Chinese social media landscape is introduced, and the profiles of Chinese digital customers are presented with the aim of informing enterprises about the key features of Chinese social media strategies. In addition, the predominant use of Chinese social media marketing is elucidated and analyzed based on several case studies. We then highlight the challenges for both local and multinational corporations when they are involved in Chinese social media marketing. We discuss current trends in Chinese social media, including cross-platform cooperation and integrated social media, group buying, and mobile social media. Finally, we offer recommendations for companies that wish to successfully engage with Chinese consumers through social media.
\end{abstract}

\section{Keywords}

Social media; Social media strategies; Social media marketing; Word-of-mouth; Social marketing plan; Business communication strategies; Chinese digital consumer; China.

\section{Resumen}

Algunas de las economías y mercados más atractivos se encuentran en los países emergentes. Este es el caso de China, que posee uno de los mercados más atrayentes a nivel internacional. La Web, y especialmente los medios sociales, han demostrado ser una herramienta clave para penetrar en este mercado. Este artículo describe las principales características tanto de las plataformas sociales chinas como de sus usuarios. Lo hace con un enfoque corporativo, con la intención de dar a conocer a las empresas aspectos clave para sus estrategias de marketing y comunicación online. En este sentido, se mencionan las oportunidades que generan la integración de medios sociales y comercio electrónico, la compra en grupo, o tener presencia en plataformas sociales adaptadas a dispositivos móviles. Además, se describen diferentes casos de estudio, todos ellos campañas de marketing de éxito, en los medios sociales chinos. El artículo concluye con algunas recomendaciones para aquellas empresas que deseen desarrollar una campaña de marketing en medios sociales de China. 


\section{Palabras clave}

Medios sociales; Estrategias en medios sociales; Marketing en medios sociales; Estrategias de comunicación empresarial; Boca-oído; Consumidores digitales chinos; China.

He, Xia; Pedraza-Jiménez, Rafael (2015). "Chinese social media strategies: Communication key features from a business perspective". El profesional de la información, v. 24, n. 2, pp. 200-209.

http://dx.doi.org/10.3145/epi.2015.mar.14

\section{Introduction}

Social media (video sharing sites, wikis, photo sharing sites, social network sites, microblogs, etc.) has already become a part of daily life for many Internet users in the world.

With the rapid development of social media a lot of corporations use it to their advantage for their brands, services, and public relations. At the same time, the public makes the most of social media for daily life including online purchasing, news reading, product information searching, and for many other services and forms of entertainment.

The concept 'Web 2.0' was first presented in the O'Reilly Media Web 2.0 conference in 2004 (Graham, 2005). Since then, Web 2.0 has led the evolution of social media (Kaplan; Haenlein, 2010). Currently, there are various social media definitions; one of the most popular is:

'Social media is a group of Internet-based applications that build on the ideological and technological foundations of Web 2.0, and that allow the creation and exchange of user generated content' (Kaplan; Haenlein, 2010).'

In his e-book, What is social media?, Mayfield (2008) indicates social media has several features including participation, openness, and community; and six types of platforms -social networks, blogs, wikis, podcasts, forums, content communities, and microblogging. Kietzmann et al. (2011) describe seven functional blocks of social media: identity, conversations, sharing, presence, relationships, reputation, and groups.

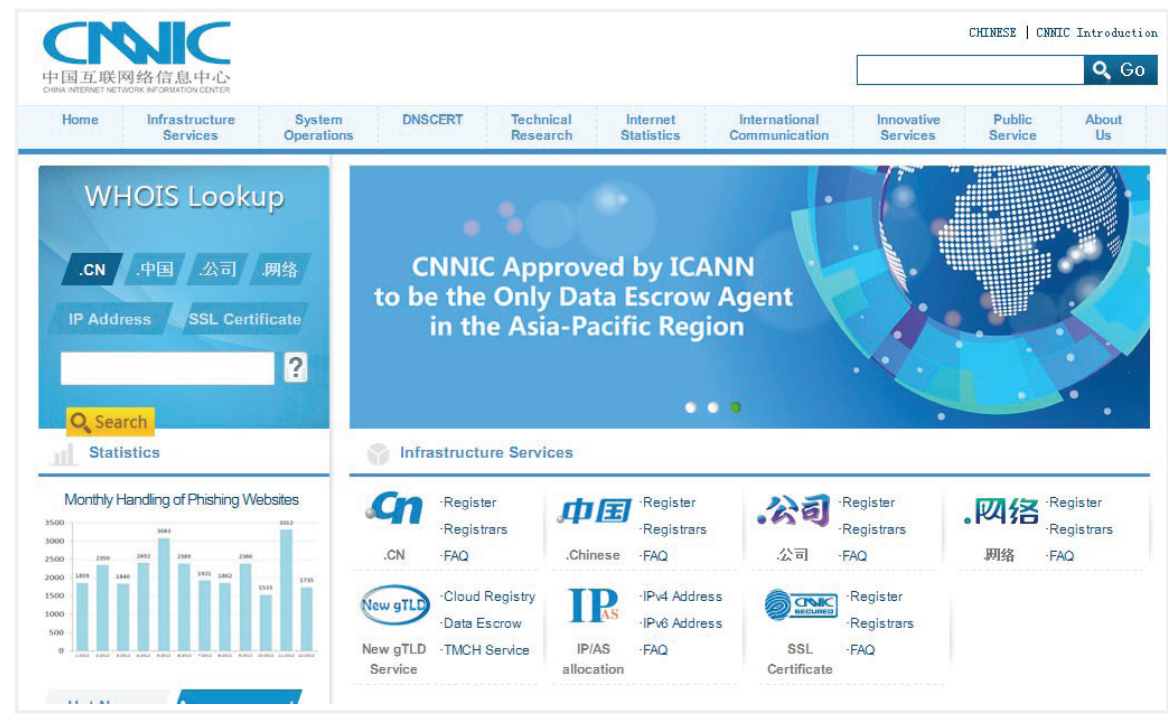

http://www1.cnnic.cn
Gupta (2011) forecasted that revenue from advertising, games, and subscriptions from global social media channels would hit $\$ 29$ billion by 2015 ; that is more than four times the amount from all of 2010 . So, it seems that we are in a new dynamic era of digital engagement and social media plays an important role in this context. More and more companies are using social media applications to collect positive and negative information about their products and services and to engage with their target audience. All these strategies improve their brands' awareness and market share (Abedniya; Mahmouei, 2010; Culnan; McHugh; Zubillaga, 2010; Moran; Gossieaux, 2010).

It's worth pointing out that in the context of globalization the most attractive economies are located in emerging markets. China, as one of the most appealing markets, has been drawing the attention of local and multinational enterprises, especially the latter with a focus on occidental corporations in China. According to the latest report on Internet development in China from China Internet Network Information Center (CNNIC), Chinese Internet users' numbers hit 618 million by the end of December 2013. The Internet penetration rate was $45.8 \%$. In the context of the enterprises these data show that $83.2 \%$ of the enterprises used the Internet to conduct official business, $23.5 \%$ to perform online sales, and $20.9 \%$ to implement marketing and promotion (CNNIC, 2014a).

This article begins by describing China's unique social media landscape by reviewing its historical roots and drawing comparisons with its Western counterparts. In order to help local and multinational enterprises better understand the key features of Chinese social media the profiles of Chinese digital consumers are also presented and categorized into several different groups. Afterwards, the predominant uses of Chinese social media marketing such as cross-platforms communication, group buying, and mobile social media marketing are discussed in several case studies. Moreover, this paper demonstrates the challenges that local and multinational enterprises may encounter while engaging with Chinese social media consumers. Finally, conclusions are drawn and some recommendations are made for marketers to formulate suitable Chinese social media strategies. 


\section{China's social media landscape}

Popular global social media platforms such as Facebook, Twitter, and YouTube dominate the occidental regions and several Asian countries. But most are inaccessible to the public in China. A brief summary of the history of Chinese social media is of importance to more fully understand the unique and complex Chinese social media landscape.

The first bulletin board system (BBS) was built in 1994 and Chinese netizens quickly began to engage within online forums and communities; one such example was the famous BBS Xicihutong (xici.net). In the beginning of the 1990s computers were luxury products to the ordinary people of China-there were few Internet users.

The real Internet boom in China began with the emergence of instant messaging (IM) with QQ, which was launched by Tencent in 1999. Millions of young people and college students started to chat with friends, or to make new friends, via the $Q Q$ platform, which was similar to ICQ (I seek you). BlogChina (blogchina. com), another revolutionary tool, was released in 2002 by founder Fangxingdong. In addition to IMing, Chinese netizens were enthusiastic about blogging, social network sites (SNS), microblogging platforms, and other social media applications. Relevant examples include the attractive social networking service Kaixinwang (kaixin001.com) in 2008; the popular microblogging channel Sina Weibo (d.weibo.com) in 2009; the convenient location-based service (LBS) Jiepang (jiepang.com) and group buying site Meituan (meituan.com) in 2010; and the fascinating mobile app Wechat platform (Weixin in China) in 2011.

Nowadays, Chinese digital users normally have several social media accounts and integrate blogging, SNS, microblogging, online picture sharing, and online video sharing. In fact, not only the normal Internet users, but also the professional news websites (for example: People's daily) are accustomed to utilizing local social media applications to meet their needs (Lim, 2014). The landscape of Chinese social media is continuously undergoing fast-paced changes and has become a rich and diverse ecosystem of social media.

Currently, Social media in China is experiencing impressive growth. It is worth mentioning that Chinese social media applications are not copies of their Western equivalents, but instead they are new creations that have been innovated to meet Chinese netizens' habits and behaviour, even if they were initially built based on some functions and characteristics of their Western counterparts (Sullivan, 2014). Today some Chinese social media

\section{正月十五闹元宵 把百万现金红包! 点击开诋}
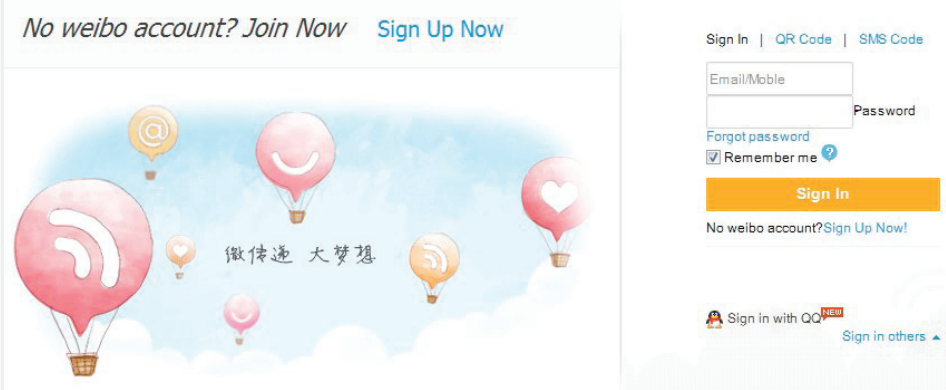

http://www.weibo.com/login.php?lang=en-us

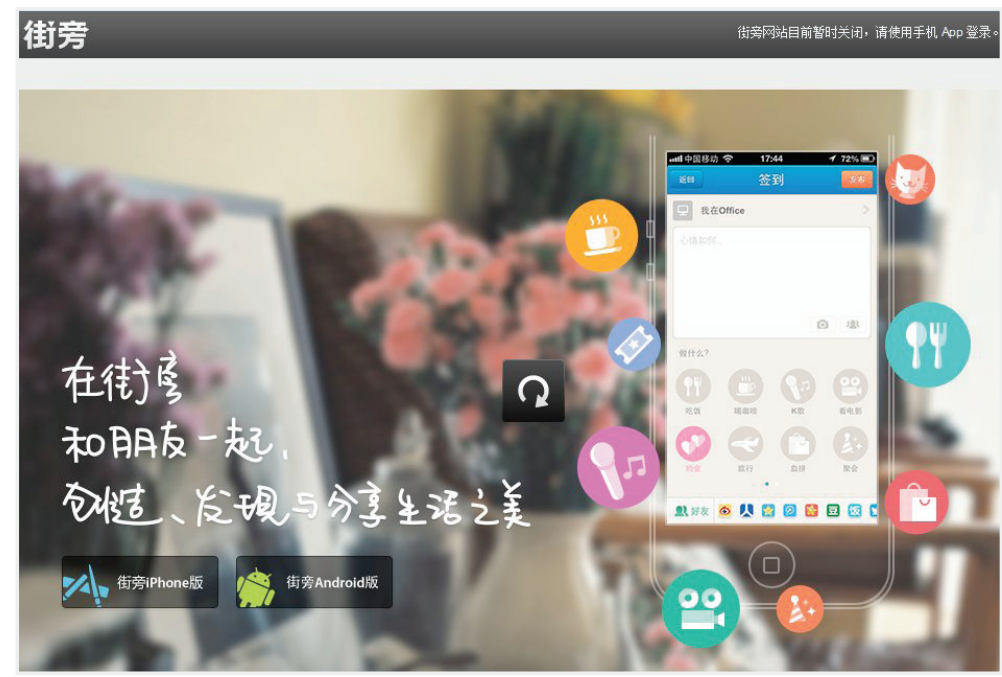

http://jiepang.com

\section{开心网}

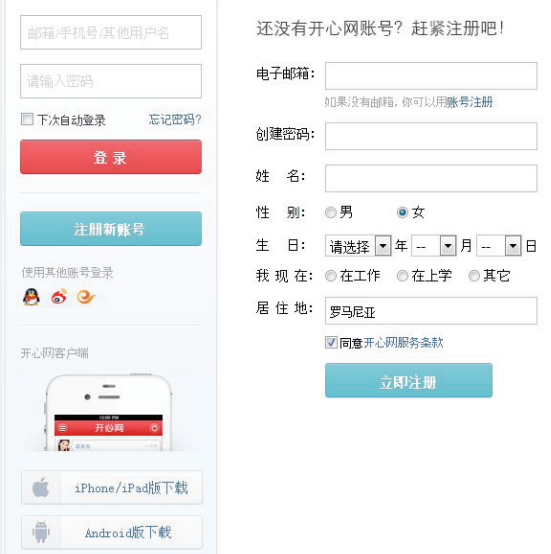

http://www.kaixin001.com
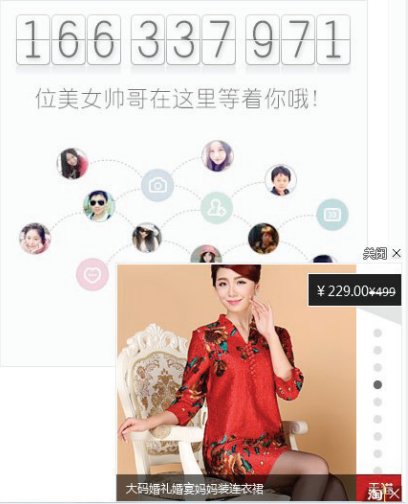

innovations are even leading the global trend of social media development. For example, Weixin (similar to WhatsApp) offers multiple features such as voice and text messaging, shaking the handset to look for friends, as well as a social networking function with the name WeChat friends. The interesting features of this application have led some 
Table 1. Popular Chinese social media platforms with their occidental counterparts

\begin{tabular}{|l|l|l|}
\hline Social media types & $\begin{array}{c}\text { Chinese social media } \\
\text { platforms }\end{array}$ & \multicolumn{1}{|c|}{$\begin{array}{c}\text { Occidental } \\
\text { counterparts }\end{array}$} \\
\hline Microblogging & $\begin{array}{l}\text { Sina Weibo; } \\
\text { Tecent Weibo }\end{array}$ & Twitter \\
\hline Social network sites & $\begin{array}{l}\text { Qzone; Renren; } \\
\text { Kaixin; WeChat friends }\end{array}$ & Facebook \\
\hline Video sharing sites & Youku; Tudou & YouTube \\
\hline Photo sharing sites & Bababian; Babidou & Flickr \\
\hline Instant messaging & QQ & MSN \\
\hline Q\&A & $\begin{array}{l}\text { Tianya Wenda; } \\
\text { Baidu Zhidao }\end{array}$ & Answers \\
\hline Wikis & $\begin{array}{l}\text { Hudong Baike; } \\
\text { Baidu Baike }\end{array}$ & Wikipedia \\
\hline LBS & Jiepang & Foursquare \\
\hline
\end{tabular}

experts to consider it better than WhatsApp. Information about this leadership of Chinese platforms can be found even in the Spanish newspaper El pais (Aldama, 2013). As a result, China is becoming one of the most active players in the social media world. The following table (table 1) shows some of the most popular Chinese social media platforms alongside their occidental counterparts.

It should be kept in mind that almost everyone has a $Q Q$ account in China and $Q Q$ is linked to Qzone (qzone.qq.com, a social network similar to Facebook). Both $Q Q$ and Qzone belong to Tencent holdings. In this way, Qzone bears a significant user base. In addition, other top social networks in China include Kaixin and Renren. And the top two social media platforms are Weixin (355 million monthly active users) and Sina Weibo (129 million monthly active users) (Xu, 2014). In general, the Chinese social media ecosystem is very special and different from its counterparts in other countries. In fact, these platforms 'live' in a complicated, competitive, and quick changing environment. It is stan- dard in China for every social media platform to have several 'brands' that belong to different companies. All Chinese social media tools are designed and built by local corporations. Therefore, China's social media landscape has the following characteristics: unique, complex, fragmented, and local.

\section{Chinese digital consumers}

In order to better understand Chinese social media marketing and engage with Chinese digital consumers effectively it is necessary to explore users' characteristics. Each social media site attracts specific user groups (Sullivan, 2012), for instance, Renren (renren.com) serves mostly college students; $Q Q$ hosts a lot of lower income digital consumers who connect via mobile phones; and Sina Weibo attracts white-collar employees with higher incomes and educational backgrounds.

The number of fans is an important indicator to test whether a social media user has received much attention. Moreover, contributions to social media development, which are composed of original content, forwarding content, and comments can show clearly whether a digital account is active. Normally there exist several types of Chinese digital consumers that can be identified by the number of followers and their contributions. Table 2 presents a classification of Chinese digital consumers.

\subsection{Celebrities and Web stars}

Celebrities and Web stars denote super stars and famous persons respectively in cyber space. Normally, these people have a tremendous amount of fans and followers on social media platforms.

Celebrities include singers, movie stars, writers, and sports stars and are well known to the public because they often appear on TV and in magazines and newspapers. Although they contribute limited content, almost every comment and tweet they post may be reposted or retweeted by numerous fans. It's of no doubt that they have a huge influence on any topic of their choosing. Therefore, most of them are opinion leaders. However, it's important to point out that Web stars were normal people before they became famous. With their own purposes and motivations some conduct unusual and shocking activities with their backroom team's planning and support. They contribute a lot to online communities' hot topics and enrich the public's leisure life. One example of a normal person turned Web celebrity is Fengjie, whose real name is Luo Yufeng; she became a Web star because of her incredibly high standards for marriage-seeking.

\subsection{Pundits / experts}

Pundits are highly qualified people who make their commentaries or viewpoints in a specific field in which they are considered an expert. They tend to focus on particular topics and give advice for neti- 
zens. They are also very active within the online community and participate in in-depth discussion. In addition, they have great influence on purchase decisions for those Internet users who trust them. In other words, they are the key opinion leaders and the main contributors of word-of-mouth in the digital era. Understanding the impact of electronic word-of-mouth is of importance for brands (Kozinets et al., 2010; Trusov; Bucklin; Pauwels, 2009). Today, due to the context of the current specific and unique Chinese social culture, ordinary Chinese citizens do not trust advertising information from large institutions. According to the report Blue book of social mentality: Annual report on social mentality of China (2012-2013) conducted by the Institute of Sociology under the Chinese Academy of Social Sciences, the social trust index has declined further in China, reflecting the relationship between the authorities (officials, police, medical staff...) and the public (Wang; Yang, 2013). Currently, the public prefers word-of-mouth from social media channels and recommendations from pundits, friends, and acquaintances.

\subsection{Content curators and retweeters}

The scholar Bhargava (2009) believed content curators would be an important role in the future of social media and stated,

'a content curator is someone who continually finds, groups, organizes and shares the best and most relevant content on a specific issue online'.

Content curators reliably select quality materials and add extra value to those materials. Moreover, they do this work continually. In contrast, retweeters are less professional than content curators, but they exist in huge numbers in China. Retweeters are keen on reposting information such as text messages, photos, jokes, and videos that they find on the social media channels of celebrities, Web stars, and others. Although they seldom create original content, retweeters are still valuable for brands and services because most of them are active within online communities and maintain a large following in social media platforms.

Table 3. Functions of Chinese digital consumers on social media platforms

\begin{tabular}{|l|l|}
\hline \multicolumn{1}{|c|}{ Profiles } & \multicolumn{1}{c|}{ Functions } \\
\hline Celebrities & $\begin{array}{l}\text { Huge influence on topics they share; } \\
\text { Key opinion leaders }\end{array}$ \\
\hline Web stars & Huge influence on topics they share \\
\hline Pundits/experts & $\begin{array}{l}\text { Great influence on purchase decision for their } \\
\text { followers; } \\
\text { Contributors of electronic word-of-mouth; } \\
\text { Key opinion leaders }\end{array}$ \\
\hline Content curators & Reliable sources \\
\hline Retweeters & $\begin{array}{l}\text { Very active; } \\
\text { Maintain large following }\end{array}$ \\
\hline Visitors & $\begin{array}{l}\text { Not very active; } \\
\text { Have their own ideas on products }\end{array}$ \\
\hline Bystanders & No \\
\hline
\end{tabular}

\subsection{Visitors}

The quiet visitors spend some time daily viewing online content such as news, product information, friends' blogs, entertainment, and so on. But they seldom participate in the conversation, discussion, or response. They are not very active or noisy on the Internet. Normally they have their own ideas about products and services after reading relevant online content. However, celebrities, pundits, and friends can have positive influence over visitors.

\subsection{Bystanders}

Bystanders are spectators who seldom spend time online reading network news or product information. They don't like to follow others and have the least followers in return. Moreover, they rarely participate in online discussions and online activities because they are inactive netizens. They do not engage in meaningful online discussions and they don't post comments. Most do not even complete the registration within an online community. They have the least influence on brands and services.

Today, it's essential to understand the Chinese digital generation, which includes those who were born in a peaceful period and grew up in the digital age. The digital generation is a major consumption force and will continue to be in the future. In the book Understanding China's digital generation - A marketer's guide to understanding young Chinese consumers, the authors demonstrate that the young digital generation enjoys the online activities of surfing, searching, and shopping (Schultz; Block; Schultz, 2013).

Finally, it is important to mention the large income gap between rural and urban areas in China. The imbalance of economic development has led to the existence of different user information behavior between cities and countryside. As noted in the report from CNNIC (2014b) rural users use PCs and tablets to get online less often than urban users. Instead, they use mobile phones to access the Internet more frequently than users in cities. Furthermore, rural users spend five hours less online per week than urban users, and they make fewer e-commerce transactions.

\section{Use of Chinese social media marketing}

It is important to be aware of the leading trends in the use of social media marketing in China. Only in this way can marketers keep up with the times and run the appropriate online campaign. As stated in the mentioned report on Internet development in China (CNNIC, 2014a), online shopping, group buying, and mobile social media applications are booming currently in China. 


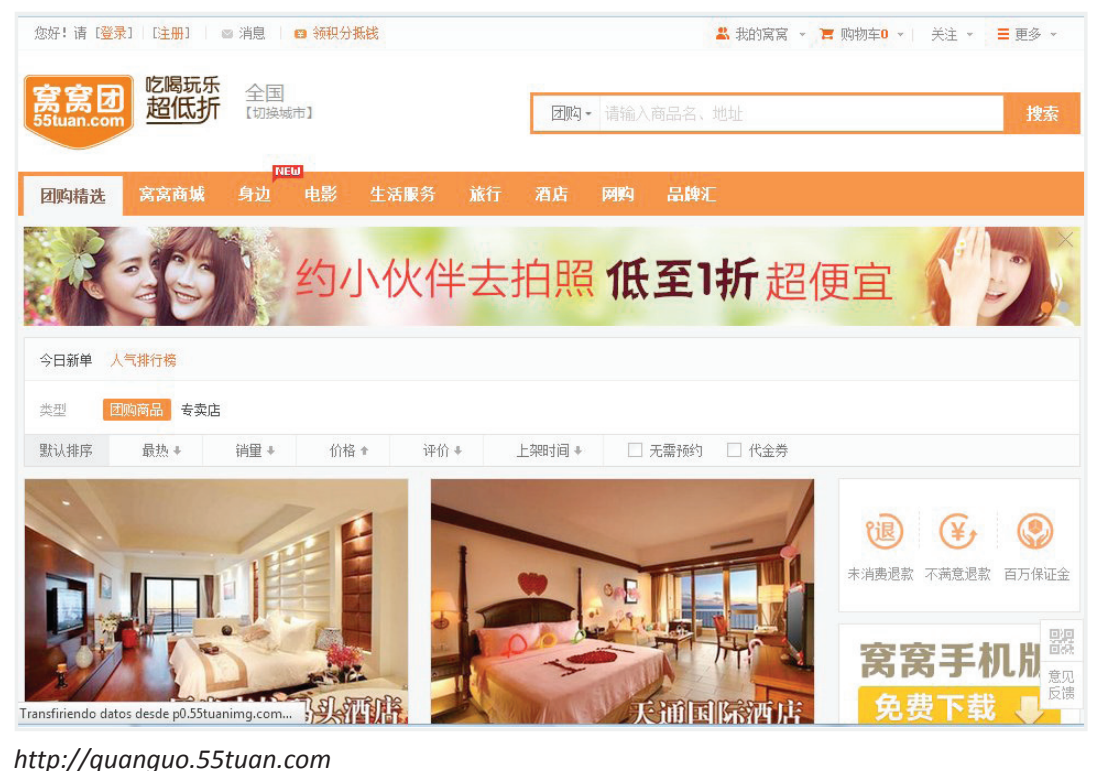

king channel. Xiaomi 1 (the first-generation of Xiaomi smartphone) sales were robust as a result of social media marketing and hunger marketing (Shen, 2012). Xiaomi 2 (the second-generation of Xiaomi smartphone) sales focused on microblogging marketing via direct vending on Sina Weibo platform in December, 2012. Sina Weibo released an advertisement, launched an online sales campaign, and built a booking page on the Weibo platform on December 19, 2012. Amazingly, Xiaomi sold out of their 50 thousands Mi2 handsets in just five minutes on December 21, 2012 using Weibo wallet-an online payment system (Chow, 2013). This tremendous effect has been continuing and a large number of comments and retweets have been emerging in Sina Weibo.

\subsection{The boom of group buying}

With the inspiration of the great success achieved by group purchase sites like Groupon, various group-buying sites are popular in China such as 55tuan (55tuan.com), Lashou (lashou.com), and Meituan (meituan.com). These group buying sites offer big discounts for a certain quantity of committed pre-orders for items and activities such as travelling, catering, and sports (Jing; Xie, 2011; Kauffman; Lai; Ho, 2010). This attractive online sales concept has led to a boom in the group purchase market in China. Chinese people prefer online shopping because of the much lower group prices and more convenient express delivery. As noted in the report published by Tuan800.com (group buying navigation website), Chinese group purchase transactions reached $\$ 5.94$ billion in 2013, which was 67.7 percent higher than the previous year (Lee, 2014). The popularity of group purchase in China is beyond many occidental people's imaginations.

Group purchase owes its popularity to attractive low prices-a result of the cooperation between group buying zens to purchase via easy link clicks after exploring the ducts' quality, price, after-sales service, etc., through twoway communications (asking, discussing, opinion exchanging, etc.) on Weibo platforms.

One representative case, from a brand that has had many successful business campaigns via Chinese social media, is from a Xiaomi online sales campaign. Xiaomi is a local brand that launched a smartphone with a media campaign in Beijing in August, 2011. Before and after the smartphone's launch there were numerous hot topics about Xiaomi's reasonable price, clean interface, and nice quality, which were discussed on social media platforms. When Xiaomi opened the online reservation for purchase on September 5, 2011 via its official website they received more than 300 thousand reservations within 34 hours. The company was forced to close the online boo-

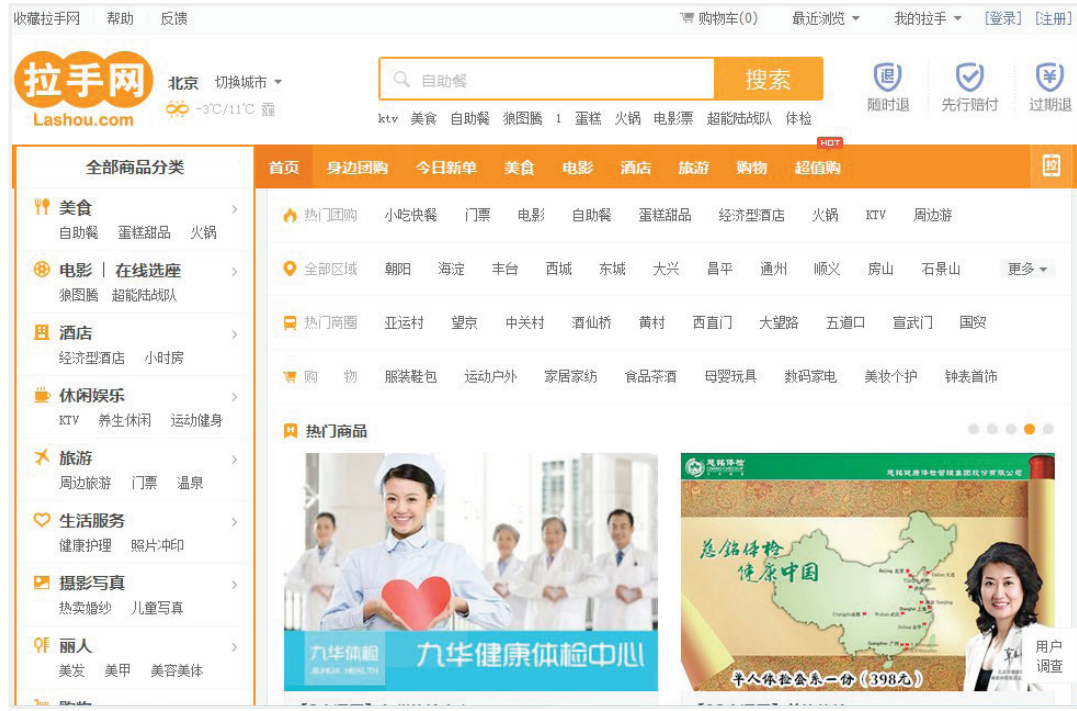

http://beijing.lashou.com 
websites and other Chinese social media platforms. It's very easy for netizens to log into the group shopping sites directly via their SNS or microblog accounts. Furthermore, Chinese digital consumers can share information about products or services from group purchase sites and can also look for participants for their deals through social media channels. The following case highlights why group purchase is very appealing and successful in China:

200 Mercedes-Benz Smart cars were offered through group online shopping site Taobao.com on September 9, 2010. Taobao provided different types of discounts depending on the number of group online buyers. When groupbuying participants reached 50 the price declined to 167,000 yuan (the original price was 176,000 yuan). When 200 participants committed to purchase the price dropped to 135,000 yuan, which meant a 33 percent discount with the group buying power for those digital consumers who committed to purchase a Mercedes-Benz smart car. Finally 205 cars were sold in three and a half hours, which made a new online buying record. It's surprising that the first car was sold after 24 seconds and 55 cars were sold after six minutes (Liang, 2010; CNN, 2010). The cars were sold so fast that it was beyond the company's expectations, because on average Mercedes-Benz sells one Smart car per day in China (CNN, 2010). This online campaign demonstrates that group purchase is popular, not only for low priced products, but also for expensive goods such as cars and home appliances because of the increase in the affluent class in China.

\subsection{The power of mobile social media marketing}

The US Pew Research Center predicts mobile devices will be the first choice for the majority of Internet users to get online in the world by 2020 (Anderson; Rainie, 2008; Kaplan; Haenlein, 2010). At present, handheld devices play an important role in the daily life and also have a profound influence on politics, economy, and culture. With the popularity of smart phones, various mobile phone apps have become the fastest growing part of the social media industry. Kaplan defined mobile social media:

'as a group of mobile marketing applications that allow the creation and the exchange of user-generated content' (Kaplan, 2012).

In China, mobile Internet users had reached 500 million by the end of 2013. Among all the Internet users, 81 percent of them used mobile devices to access the Internet, according to the latest report from China Internet Network Information Center (CNNIC, 2014a). In other words, Chinese people prefer mobile devices for surfing the Internet for entertainment and online purchases. As indicated in the report, each day 75.6 percent of users used mobile browsers for webpage browsing, news reading, etc. In addition, mobile maps and mobile e-commerce are becoming in- creasingly popular in China. In particular, mobile e-commerce has been making great strides in the e-commerce industry, which can partly be attributed to the maturing mobile payment system.

\section{Challenges}

It is crucial to run a social media campaign to engage with digital consumers and accelerate brand awareness, which ultimately increases sales in the digital age. However, actual operationalization of engagement, for both local enterprises and multinational enterprises, faces many challenges.

\subsection{Challenges for the local enterprises}

Social media is still a relatively new concept for many local firms because it has not gone through a long period of development in China. In the beginning of the Web 2.0 era, most Chinese companies did not realize they would be starting a new marketing campaign and engaging with digital consumers.

With the boom of blogs, a few corporations began to build an official corporate blog to enhance their brand awareness and enterprise culture. A thriving social media landscape began to take shape with the launch of microblogging and SNS, capturing millions of Internet users. More and more local enterprises have recognized the benefits of social media marketing and have tried to engage with the existing and new customers via diversified social media platforms. Nevertheless, local companies are still facing some challenges in the process of running social media campaigns. Forrester Research interviewed 24 leading local enterprises with rich social media marketing experience and generated a report in 2013. As this report noted, Chinese companies face mainly four big challenges in the usage of social media for their brands and services (Dink in Forrester, 2013):

\section{Lack of clear social media strategies}

Half of the 24 companies considered building an effective social media strategy their biggest challenge. Due to the short history of Chinese social media marketing and few successful cases, they have had to learn through trial and error. 


\section{Difficulty to measure social media marketing efforts}

Most of the companies took into account increasing brand preference as their primary objective. However, 12 respondents claimed they did not have an effective mechanism to measure the social media marketing outcome.

\section{Understaffing for social media team}

Half of 24 local enterprises had a social media team with less than three employees. Understaffing is a common phenomenon for local firms.

\section{Lack of professional consulting from agency}

Generally, local enterprises don't employ agencies to deal with issues of originality, traditional media, and social media in the Chinese market. In fact, only 11 firms confirmed they had hired agencies to handle social media marketing.

\subsection{Challenges for the multinational enterprises}

Marketers in the occidental region, America and Europe, have achieved success by using powerful tools such as Facebook, YouTube, Google, and Twitter to run online campaigns in their region. But they face some new challenges when they play the Chinese social media game.

\section{Unfamiliar with local social media platforms}

Multinational marketers are confronting an entirely new social media ecosystem and they have to forget the most recognized social media platforms in the West. Instead, they need to know and consider new Chinese platforms with names like Sina Weibo, Tencent QQ, Renren, Kaixin, Youku, etc.

\section{Lack of understanding of Chinese digital consumers}

Chinese digital consumers are different from their Western counterparts. Multinational enterprises have to give up the approach they used with the occidental digital consumers. So it is necessary for them to understand the Chinese netizens' habits and behavior in order to engage differently with their own target audience.

\section{Difficulty to identify the right platforms}

Many multinational enterprises are not clear about how to select the right social media platform for their business because the Chinese social media landscape is more complex and fragmented than its Western counterparts. For instance, Weibo (Twitter-style microblog) comprises Sina Weibo, Tencent Weibo, Sohu Weibo, etc. Each of them attracts a different group of digital consumers. So marketers need to choose the most suitable one to engage with their target audience.

\section{Difficulty to measure social media ROI (return on inves-} tment)

This is similar to the challenge mentioned in section 5.1.. According to a social media marketing industry report (2013) from social media examiner, 87 percent of marketers have no idea how to measure their ROI for their social media campaigns. In the last three years this question has become a big problem for marketers (Stelzner, 2013). Multinational companies have even more difficulty in measuring their social media marketing efforts in the complex Chinese social media environment when compared to their domestic environment.

\section{Conclusions and recommendations}

It has been found that the unique Chinese social media landscape is very different from its Western equivalents. Chinese digital consumers demonstrate unique Internet behaviors and habits which result in distinctly different user profiles as a result of differing internet customs and cultures. Cross-platform cooperation and integrated social media strategies have become the new trend in Chinese digital marketing. Group purchase had promoted the rapid growth of online shopping in recent years in China. Chinese mobile social media marketing is becoming more and more popular and alluring for brands and services. This new phenomenon implies that fingertips economy should not be ignored. However, it's worth pointing out that local and multinational enterprises face some big challenges when they run social media campaigns in the potential Chinese market. Based on our analysis, some relevant recommendations can be made for local and multinational corporations as they plan Chinese social media strategies.

\subsection{Do market research and digital consumer research}

Before building the social media strategy, marketers need to conduct some research to better understand the Chinese market and online customers. Marketers can use traditional methods to do this work, but they can also use web analytics tools that are supported by these platforms. Only in this way can marketers obtain the relevant data and information about their industries. Not only local companies, but also multinational companies need to pay more attention to these primary investigations. Based on this research they can build a clear and effective social media strategy in the Chinese market.

\subsection{Listen to WOM (word-of-mouth)}

Marketers and digital consumers have known for years that word-of-mouth has become the core point of growing interest. It's no doubt that electronic word-of-mouth (eWOM) has great influence on brands and services in the digital era (Dellarocas, 2003; Chu; Kim, 2011; Smith et al., 2007). On the one hand, marketers consider that eWOM marketing is one of the most effective and cheapest methods of advertising within online communities. On the other hand, online shopping buyers are inclined to believe eWOM and can obtain the relevant product information from other netizens' positive or negative opinions. China Investment Corporation $(\mathrm{ClC})$, a think tank based on Chinese social business, created the similar concept of IWOM (Internet word-of-mouth) and proposed that it's important to listen to IWOM, not only collect industry information, but also to evaluate a brand's online reputation (CIC, 2011). It's advisable for marketers to pay attention to IWOM while digital customers happily share and exchange their viewpoints on products and services online.

\subsection{Identify the KOLs (key opinion leaders)}

In China social media KOLs have great influence on purchase decisions for consumers due to particularities within Chinese culture, where online shopping customers distrust advertising and information from big institutions and authorities. Regarding the users' new media contact behavior, the 
Weighted and calculated needs theory for new media states that users will seek and use an especial new media only when the conventional media fail to satisfy their specific need that is important to realize their purpose in life (Zhu, 2004). In China, digital users adopt and use social media to satisfy a certain need when the relevant information and advertising from formal institutes cannot meet their requirements. In fact, they prefer to purchase products that are recommended by key opinion leaders on social media channels. These KOLs may be celebrities, pundits, Internet influencers, Web stars, or trend-setters who are active and influential within online communities. They share their product experience, contribute professional information, and even provide purchase advice to their followers. All these online behaviors greatly affect consumers' purchase decisions. Therefore, marketers must know and find the key opinion leaders in their industries and social media applications, and then maintain a good relationship with those KOLs.

\subsection{Mind the young generation}

Today social media is indispensable to the public in China, especially to the young generation who grew up in the digital era; they are inclined to focus on individual character development and a certain kind of freedom of expression. Social media platforms offer personal space for the young digital generation in which they can have not only have more privacy and liberty, but also make their own decisions. Moreover, the digital young generation knows how to handle social media tools and adapts faster to new tools than prior generations. Therefore, it's necessary to mind the young generation when companies prepare to run online campaigns.

\subsection{Attend social media marketing training courses}

In order to run more efficient social media campaigns some marketers have started to participate in professional digital marketing courses, e.g. microblogging marketing courses, SNS marketing courses, search engine marketing courses, etc. Considering that multinational enterprises normally lack an understanding of Chinese social media tools and digital customers, marketers can substantially benefit from these professional training courses. Aiming to expand Chinese market share further, several British companies such as Harrods, Westfield, and Merlin Group participated in the microblogging marketing course that was held by Sina Weibo business school in London in 2013 (Zhou, 2013). This kind of training course can help multinational enterprise managers and marketers to understand the unique Chinese social media culture, to create effective Chinese social media strategies, and to run effective social media campaigns.

\section{Acknowledgements}

China Scholarship Council under the State Scholarship Fund and Ministerio de Economía y Competitividad de España (proyecto de investigación CSO 2011-22691).

\section{References}

Aldama, Zigor (2013). "Occidente copia a China". El país, March 1.

http://tecnologia.elpais.com/tecnologia/2013/03/01/ actualidad/1362160234_435886.html
Abedniya, Abed; Mahmouei, Sahar-Sabbaghi (2010). "The impact of social networking websites to facilitate the effectiveness of viral marketing". Intl journal of advanced computer science and applications, December, v. 1, n. 6, pp. 139-146. http://goo.gl/UHIATX http://dx.doi.org/10.14569/IJACSA.2010.010621

Anderson, Janna Q.; Rainie, Lee (2008). The future of the internet III. Pew research internet project. http://www.pewinternet.org/files/old-media//Files/ Reports/2008/PIP_Futurelnternet3.pdf.pdf

Bhargava, Rohit (2009). "Manifesto for the content curator: The next big social media job of the future". IMG, September 30. http://www.rohitbhargava.com/2009/09/manifesto-for-thecontent-curator-the-next-big-social-media-job-of-the-future.html

Chiu, Cindy; Lin, Davis; Silverman, Ari (2012). China's socialmedia boom. McKinsey \& Company.

https://s3-ap-northeast-1.amazonaws.com/mckinseychinavideos/ PDF/McKinsey-Chinas-Social-Media-Boom1.pdf

Chow, Low-Lai (2013). "How brands can use Sina Weibo to reach Chinese consumers". Warc. Event reports. Festival of media Asia, March.

http://goo.gl/Cn531E

Chu, Shu-Chuan; Kim, Yoojung (2011). “Determinants of consumer engagement in electronic word-of-mouth (eWOM) in social networking sites". Intl. journal of advertising, v. 30, n. 1, pp. 47-75.

http://goo.gl/SjUHTG

http://dx.doi.org/10.2501/IJA-30-1-047-075

CIC (China Investment Corporation) (2011). From social media to social business, topic one: an overview of the evolution of Chinese social media. A CIC social business white paper. http://vdisk.weibo.com/s/9EcVm

CNN (2010). "Taobao sells 205 Benzes in just over three hours". CNN, September 17.

http://travel.cnn.com/shanghai/shop/taobao-sells-205benzes-just-over-three-hours-653638

CNNIC (2014a). The $33^{\text {rd }}$ statistical report on internet development in China. China Internet Network Information Center. http://www1.cnnic.cn/IDR/ReportDownloads/201404/ U020140417607531610855.pdf

CNNIC (2014b). The report on internet development in rural China in 2013. China Internet Network Information Center (in Chinese).

http://www.cnnic.cn/h/wfzyj/h/wxzbg/ncbg/201406/ P020140611558782533389.pdf

Culnan, Mary J.; McHugh, Patrick; Zubillaga, Jesus I. (2010). "How large US companies can use Twitter and other social media to gain business value". MIS quarterly executive, v. 9, n. 4, pp. 243-259.

http://misqe.org/ojs2/index.php/misqe/article/view/342

Dellarocas, Chrysanthos (2003). "The digitalization of word of mouth: Promise and challenges of online feedback mechanisms". Management science, v. 49, n. 10, pp. 1407-1424. http://ccs.mit.edu/dell/digitization\%20of\%20word-ofmouth.pdf 
http://dx.doi.org/10.1287/mnsc.49.10.1407.17308

Dink in Forrester (2013). "Chinese enterprises face 4 challenges in social media marketing" (in Chinese).

http://www.199it.com/archives/169264.html

Graham, Paul (2005). "Web 2.0". Paul Graham, November. http://www.paulgraham.com/web20.html

Gupta, Neha (2011). "Forecast: social media revenue, worldwide, 2010-2015". Gartner, Stamford, CT, September 23.

https://www.gartner.com/doc/1802617/forecast-socialmedia-revenue-worldwide

Jing, Xiaoqing; Xie, Jinhong (2011). “Group buying: A new mechanism for selling through social interactions". Management science, v. 57, n. 8, pp. 1354-1372.

http://dx.doi.org/10.1287/mnsc.1110.1366

Jingting, Shen (2012). "Xiaomi, China's Apple success story?" China daily, June 7.

http://www.chinadaily.com.cn/business/2012-06/07/ content_16064278.htm

Jun, Liang (2010). "Taobao sells 205 Benzes within 3.5 hours". People's daily online, September 14.

http://english.peopledaily.com.cn/90001/90776/90882/7139958. html

Junxiu, Wang; Yiyin, Yang (eds.) (2013). Blue book of social mentality: Annual report on social mentality of China (20122013). China: Social Sciences Academic Press (in Chinese). ISBN: 9787509722121

http://goo.gl/XSrz2R

Kaplan, Andreas M. (2012). "If you love something, let it go mobile: Mobile marketing and mobile social media $4 \times 4$ ". Business horizons, v. 55, n. 2, pp. 129-139.

http://dx.doi.org/10.1016/j.bushor.2011.10.009

Kaplan, Andreas M.; Haenlein, Michael (2010). "Users of the world, unite! The challenges and opportunities of social media". Business horizons, v. 53, n. 1, pp. 59-68.

http://dx.doi.org/10.1016/j.bushor.2009.09.003

Kauffman, Robert J.; Lai, Hsiangchu; Ho, Chao-Tsung (2010). "Incentive mechanisms, fairness and participation in online group-buying auctions". Electronic commerce research and applications, v. 9, n. 3, pp. 249-262.

http://dx.doi.org/10.1016/j.elerap.2008.11.009

Kietzmann, Jan; Hermkens, Kristoffer; McCarthy, Ian P.; Silvestre, Bruno S. (2011). "Social media? Get serious! Understanding the functional building blocks of social media". Business horizons, v. 54, n. 3, pp. 241-251.

http://papers.ssrn.com/sol3/papers.cfm ?abstract_ $i d=2519365$

http://dx.doi.org/10.1016/j.bushor.2011.01.005

Kozinets, Robert V.; De-Valck, Kristine; Wojnicki, Andrea C.; Wilner, Sara J. S. (2010). "Networked narratives: Understanding word-of-mouth marketing in online communities". Journal of marketing, v. 74, n. 2, pp. 71-89.

http://www.etnografiadigitale.it/wp-content/uploads/2012/04/ Networked_Narratives_JM2010_Final_SM.pdf http://dx.doi.org/10.1509/jmkg.74.2.71
Lee, Emma (2014). “2013 China's group-buying turnover rockets $67.7 \%$ YOY to 35.88 billion Yuan". TechNode, January 15. http://technode.com/2014/01/15/2013-group-buyingturnover-rockets-68-percent-yoy-in-china

Lim, Jeongsub (2014). "A model of functional rules for social media in the networked news sphere". Asian journal of communication, v. 24, n. 3, pp. 279-294.

http://dx.doi.org/10.1080/01292986.2013.877041

Mayfield, Antony (2008). What is social media. iCrossing. http://www.icrossing.co.uk/fileadmin/uploads/eBooks/ What_is_Social_Media_iCrossing_ebook.pdf

Moran, Edward; Gossieaux, François (2010). "Marketing in a hyper-social world: The tribalization of business study and characteristics of successful online communities". Journal of advertising research, v. 50, n. 3, pp. 232-239.

http://www.iei.liu.se/fek/svp/mafo/artikelarkiv/1.309542/B5.pdf http://dx.doi.org/10.2501/S0021849910091397

Schultz, Heidi; Block, Martin P.; Schultz, Don E. (2013). Understanding China's digital generation: A marketer's guide to understanding young Chinese consumers. USA: Prosper Publishing, pp. 101-124. ISBN: 9780984875610

JSmith, Ted; Coyle, James R.; Lightfoot, Elizabeth; Scott, Amy (2007). "Reconsidering models of influence: The relationship between consumer social networks and word-ofmouth effectiveness". Journal of advertising research, v. 47, n. 4, pp. 387-397.

http://dx.doi.org/10.2501/S0021849907070407

Stelzner, Michael A. (2013). 2013 Social media marketing industry report: how marketers are using social media to grow their businesses. Social Media Examiner. http://goo.gl/qUk4yo

Sullivan, Jonathan (2012). "A tale of two microblogs in China". Media, culture \& society, v. 34, n. 6, pp. 773-783.

http://dx.doi.org/10.1177/0163443712448951

Sullivan, Jonathan (2014). "China's Weibo: Is faster different? New media \& society", v. 16, n. 1, pp. 24-37. http://dx.doi.org/10.1177/1461444812472966

Trusov, Michael; Bucklin, Randolph E.; Pauwels, Koen (2009). "Effects of word-of-mouth $v$. traditional marketing: Findings from an internet social networking site". Journal of marketing, v. 73, n. 5, pp. 90-102.

http://dx.doi.org/10.1509/jmkg.73.5.90

Xu, Tianyu (2014). "Social, digital \& mobile in China 2014". We are social, 13 April.

http://wearesocial.sg/blog/2014/04/social-digital-mobilechina-2014

Zhou, Zhao-Jun (2013). British enterprises expand Chinese market share with the help of social media, June 15 (in Chinese). http://media.people.com.cn/n/2013/0615/c4060621848979.html

Zhu, Jian-Hua (2004). "Competition between alternative sources and alternative priorities: A theory of weighted and calculated needs for new media". China media report, v. 8, n. 2, pp. 16-24 (in Chinese). 